\title{
An Empirical Examination of the Arbitrage Pricing Theory: Evidences from the U.S. Stock Market
}

\author{
Mahdy F. Elhusseiny, Nyakundi M. Michieka, Benjamin Bae \\ California State University, California, USA
}

\begin{abstract}
This study investigates the effects of changes in local macroeconomic risk factors on returns on the banking, chemicals, insurance, telecommunication, and utilities industries in the U.S. market. Using a multifactor pricing model and data from 1998:01 to 2017:12, empirical results show that the banking, chemical, and telecommunication industries show more differences in their stock reactions to local macroeconomic risk factors. The insurance and telecommunication industries do not react significantly to risk factors. However, all the industries show strong reactions to local market portfolio.
\end{abstract}

Keywords: arbitrage pricing theory, macroeconomic factors, multifactor pricing model

\section{Introduction}

Pricing of financial asset has been one of the hot topics in the area of finance for a long time. Most of the earlier studies have been based on the dominant models within single factor Capital Asset Pricing Model (CAPM) as developed by Sharp (1964), Lintner (1965), Black, Jensen, and Scholes (1972), and Fama and McBeth (1973). Basically, CAPM is applied in these models and market index is the only relevant factor in measuring an asset's systematic risk. However, it is evidenced that a lot of empirical studies based on CAPM fail to show a clear relationship between the stock return and market beta.

Fama and Fench (1992) indicated that there are significant effects on asset returns of a set of microeconomic and company specific factors, such as size and book-to-market ratio in addition to the market portfolio. These studies imply that market portfolio alone may not fully measure an asset's systematic risk.

Roll (1977) and Roll and Ross (1980) were the early studies that for the first time introduced the Arbitrage Pricing Theory (APT) as an alternative for CAPM. APT hypothesizes that asset returns are dependent on several types of risk factors. However, APT also fails to identify the relevant factor structure that can explain the variations in stock returns.

Hence, researchers looked for other risk factors. They concluded that macroeconomic factors could influence cash flows and available investment opportunity structure of the firm. Chen, Roll, and Ross (1986) was the first studied that investigated a set of macroeconomic factors as proxies for undefined state variables in APT and also examined their influence on stock returns.

Mahdy F. Elhusseiny, professor, Department of Accounting and Finance, School of Business and Public Administration, California State University, California, USA.

Nyakundi Michieka, assistant professor, California State University, California, USA.

Benjamin Bae, professor of Accounting, California State University, California, USA. 
However, empirical results of this line of study showed great deal of variations in the causal relationship between the stock returns and macroeconomic factors, depending upon the sets of macroeconomic factors used. These variations in the results seem to warrant further empirical researches that examine the model using different stock markets with different time periods. Hence, the findings of this paper based on additional measures should help better understand this important relationship between macroeconomic factors and stock returns.

To the knowledge of the authors, no study has been conducted for the U.S. stock market. Thus, the objective of our study is to investigate the effects of several key macroeconomic factors on different industries' stock performances measured by stock returns. Specifically, one major research question to be addressed is whether or not and to what extent do returns on industries react to macroeconomic risk factor changes. Mostly previous studies have examined the effect of different sets of risk factors on the returns of either individual or portfolios of stocks without considering the industry type. Investigating the returns at the industry level is of interest in its own right. Hence, it seems imperative to investigate the relationship between the macroeconomic factors and industry stock returns in the U.S. stock markets

In this study, we employ a multifactor pricing model to investigate effects of several macroeconomic risk factors on industry stock returns in the U.S. based on Chen, Roll, and Ross (1986) methods. A number of macroeconomic factors are used as explanatory variables of industry stock returns using the asset pricing theory. Specifically, in our study, those local macroeconomic risk factors include industrial production, inflation, term structure, foreign exchange rate, and oil prices in addition to the returns on the national equity market portfolio. We examine returns of five different U.S. industries, such as banking, chemicals, insurance, telecommunication, and utilities as only these industry data are available.

This study is important for the following reasons. First, the findings of this study provide stock market participants with useful information about the effect of macroeconomic risk factors on industry returns. By understanding how macroeconomic factors affect industry stock returns, investors should be able to make more informed investment decisions. Second, the findings should help financial managers, such as investment bankers or mutual fund managers understand the influence of risk on returns of different industries so that they can form and/or choose the highest yield plans and choices. Thus, this paper adds to the body of literature and thus makes a significant contribution.

The remainder of the study is organized as follows: The second section describes prior literature and conceptual frameworks, while the third section discusses the research methods including the hypothesis development, empirical models, and sample selection. The empirical results are presented in the fourth section. The final section provides summary and concluding remarks.

\section{Literature Review}

Previous studies on APT have tried to identify which macroeconomic risk factors have more explanatory power in multifactor models. In this section, theories on APT and empirical tests are reviewed as follows.

Using daily data for the January 1997 to June 2002 period, Norbert Funke and Akimi Matsuda (2006) analyze similarities and differences in the impact of macroeconomic news on stock returns in the United States and Germany. For the United States, they present evidence for asymmetric reactions of stock prices to news. In a boom (recession) period, bad (good) news on GDP growth and unemployment or lower (higher) than expected interest rates may be good news for stock prices. In the period under consideration, there is little 
evidence for asymmetric effects in Germany. However, in the case of Germany, international news appears at least as important as domestic news. There is no evidence that U.S. stock prices are influenced by German news. The analysis of bi-hourly data for Germany confirms these results.

Benjamin A. Abugri (2008) investigated whether dynamics in key macroeconomic indicators, like exchange rates, interest rates, industrial production, and money supply in four Latin American countries significantly explain market returns. The MSCI world index and the U.S. three-month T-bill yield are also included to proxy the effects of global variables. Using a six-variable vector autoregressive (VAR) model, the study finds that the global factors are consistently significant in explaining returns in all the markets. The country variables are found to impact the markets at varying significance and magnitudes.

McSweeney and Worthington (2008) examined the Australian industry stock returns reactions to the crude oil prices changes. The authors use multifactor static and dynamic models that consider the macroeconomic factors including crude oil as pricing factors in industry stock returns. The data used were from January 1980 to August 2006. The macroeconomic factors used are the market portfolio, oil prices, exchange rates, and term premium. The industries chosen are banking, diversified financials, energy, insurance, media, property trusts, materials, retailing, and transportation. The study finds that oil prices have different impact on banking, energy, materials, retailing, and transportation. The study also suggests that oil prices movements are persistent.

Elhusseiny (2009) examined several local and global risk factors that might explain the variation in the Canadian industries' stock returns. Using a multifactor pricing model, the author included industrial production, inflation, changes in expected inflation, term structure of interest rate, foreign exchange rate, oil prices, and return on the national equity market. In addition, the author studied the impact of global risk factor on the national economy by using a single factor model represented by the world market index. Banking, chemical, insurance, utilities, and telecommunication industries were tested.

The test results clearly indicate that the selected macroeconomic risk factors have significant impact on some of the Canadian industry excess returns. However, the single factor model represented by the world market portfolio poorly explained the variations of the monthly excess returns across industries in Canada.

Sunil K. Mohantya, Mohan Nandhab, Abdullah Q. Turkistanic, and Muhammed Y. Alaitanic (2011) assessed the relation between changes in crude oil prices and equity returns in Gulf Cooperation Council (GCC) countries using country-level as well as industry-level stock return data. Their findings show that at the country level, except for Kuwait, stock markets have significant positive exposures to oil price shocks. At the industry level, the responses of industry-specific returns to oil shocks are significantly positive for only 12 out of 20 industries. Their study also provides evidence that oil price changes have asymmetric effects on stock market returns at the country level as well as at the industry level.

Applying the GARCH or ARCH model, Yu Hsing and Wen-Jen Hsieh (2012) found that Poland's stock market index is positively associated with industrial production or real GDP and the German stock market index, negatively affected by the government borrowing/GDP ratio, the real interest rate, the nominal effective exchange rate, the expected inflation rate, and the government bond yield in the euro area, and exhibits a quadratic relationship with the M2/GDP ratio. It suggests that the stock market index and the M2/GDP ratio show a positive (negative) relationship if the M2/GDP ratio is less (greater) than the critical value of $43.68 \%$.

Mohi-u-Din Sangmi and Mohd. Mubasher Hassan (2013) examined the effect of macroeconomic variables on the stock price movement in Indian stock market. Six variables of macro-economy (inflation, exchange rate, Industrial production, MoneySupply, Goldprice, and interest rate) are used as independent variables. Sensex, 
Nifty, and BSE 100 are indicated as dependent variables. The monthly time series data are gathered from RBI handbook over the period of April 2008 to June 2012. Multiple regression analysis is applied in this paper to construct a quantitative model showing the relationship between macroeconomics and stock price. The result of this paper indicates that significant relationship is occurred between macroeconomics variables and stock price in India.

Cyrus Mutuku and Kirwa Lelei Ng'eny (2015) investigated the dynamic relationship between stock prices and four macroeconomic variables in Kenya using cointegration and vector autoregressive framework. The VAR and VECM (vector error correction model) analysis reveals that macroeconomic variables drive equity market in the long run. The variables in the VAR model are co integrated with $3.8 \%$ disequilibrium being corrected quarterly. Notably, inflation has a negative effect on equity market suggesting that policy authorities in Kenya should design polices that mitigate inflation for stock market to develop. The results confirm that stock market is not an avenue for perfect hedge against inflation.

\section{Methodology and Data Analysis}

\section{Methodology}

APT suggests that asset returns are more sensitive to unexpected change in several macroeconomic factors since the expected change is already taken into consideration by investors when pricing the asset returns. This requires a measure to represents the unanticipated component of the macroeconomic factors in the actual time series. Univariate ARIMA (auto-regression integrated moving average) models have been widely used for this purpose. In our study, we use the ARIMA models to construct the unexpected components of the macroeconomic factors used.

To examine the effects of local macroeconomic risk factors on the returns of the five different industries being investigated, we employ a multifactor pricing model for the U.S. data. Equation (1) provides the framework for implementing that relationship. It models industries stock returns as a function of K-local macroeconomic risk factors.

$$
r_{i t}=\alpha_{i}+\sum_{j=1}^{k} \beta_{i j} F_{j t}+\varepsilon_{i t}
$$

Where $r_{i t}=$ the excess return: $r_{i t}=R_{i t}-R_{f t} ; R_{i t}=$ the return for industry $i$ at time $t$;

$R_{f t}=$ risk free interest rate; $\alpha_{i}=$ the constant term; $\beta_{i j}=$ are the betas of the $r_{i t}$ on the $k$ risk factors;

$F_{j t}=$ are the risk factors where $j=1 \ldots k$; and $\varepsilon_{i t}=$ error term, representing the non-systematic excess return relative to risk factors.

The $k$ risk factors chosen in this study include industrial production, inflation rate, term structure, foreign exchange rate, and oil price, in addition to the return on the local equity market portfolio.

\section{Data: Description and Sources}

Definition of data sets and the sample period. Two different sets of data are used. The first set includes monthly industry stock returns. The second set consists of monthly local macroeconomic factors. All monthly returns are measured for January 1998-December 2017.

Industry stock returns. All of the industry indices chosen in this study come from Global Financial Data (GFD), which utilizes the same procedures to allocate firms into industry groups. We examine stock returns of 
five different industries for which data are available. The industries chosen are insurance, banking, chemicals, telecommunications, and utilities. Industry stock returns $R_{i t}$ are calculated for each industry index, as:

$$
R_{i t}=\ln \left[\frac{R_{i t}}{R_{i t-1}}\right]
$$

Where $R_{i t}, R_{i t-1}$ are the index values of industry $I$ at time $t$ and $t-1$ respectively, in local currency. We choose the broadest index available to provide a long-term series that shows the overall trend of stocks in the U.S.

The industry stock returns $\left(R_{i t}\right)$ are in excess of the local short- term interest rate. The short-term interest rate in the U.S., the three-month treasury bill is a proxy for risk free $\left(R_{f}\right)$ rate and is used to measure excess returns for each industry.

Local macroeconomic risk factors. The choice of macroeconomic factors was dictated by their theoretical relevance to asset pricing, regardless of the location of the market. In addition, data availability on monthly frequency was also a consideration.

Based on the above approach, we selected a set of macroeconomic factors that explain the variation on the industry stock returns. These factors are industrial production, inflation rate, term structure, foreign exchange rate, oil prices, and the return on the national market portfolio. Table 1 presents the local macroeconomic factors used in the study as sources of the local risk.

Table 1

Local Macroeconomic Risk Factors Utilized in the Study

\begin{tabular}{llll}
\hline Factors & Symbol & Data source & Calculation \\
\hline Industrial production & $I P$ & GFD & $I P_{t}=\ln \left[I P_{t} / I P_{t-1}\right]$ \\
Inflation & $I$ & GFD & $I_{t}=\ln \left[P_{t} / P_{t-1}\right]$ \\
Term structure & $T S$ & GFD & $T S_{t}=L G B_{t}-T B_{t}$ \\
Foreign exchange rate & $F X$ & GFD & $F X_{t}=\ln \left[F X_{t} / F X_{t-1}\right]$ \\
Oil price & $O G$ & GFD & $O G_{t}=\ln \left[O G_{t} / O G_{t-1}\right]$ \\
Market excess return & $M K T$ & GFD & $M K T_{t}=R m_{t}-R f_{t}=\ln \left[R m_{t} / R m_{t-1}\right]-T B_{t}$ \\
\hline
\end{tabular}

Industrial production. Monthly growth rate in industrial production is calculated from the monthly industrial production index. The industrial production growth rate is the first difference in the logarithm of the monthly industrial production index of the U.S. The monthly growth rate in industrial production is calculated as follows:

$$
I P_{t}=\ln \left[\frac{I P_{t}}{I P_{t-1}}\right]
$$

The industrial production series for 1/1998 to 12/2017 was obtained from the GFD.

Inflation rate. The inflation rate for period $t$ (It) is defined as the first difference in the natural log of the monthly consumer price index of the US for period $t$ and computed using the following equation:

$$
I_{t}=\ln \left[\frac{P_{t}}{P_{t-1}}\right]
$$

The inflation series for the period 1/1998 to 12/2017 was obtained from GFD. 
Term structure. Term structure is defined as the difference between long- and short- term government interest rates. Based on availability, we use the difference between the 10-year government long-term bond yields, and three-month Treasury bill for the U.S. The following equation is employed:

$$
T S_{t}=L G B_{t}-T B_{t}
$$

These series were obtained from GFD for the period 1/1998 to 12/2017.

Foreign exchange rate. Foreign exchange rate is measured as the change from month $t-1$ to month $t$ in natural $\log$ of foreign currency exchanges of the U.S. The following equation is used

$$
F X_{t}=\ln \left[\frac{F X_{t}}{F X_{t-1}}\right]
$$

The series was obtained from GFD for the period 1/1998 to 12/2017.

Oil prices. We use the West Texas Intermediate (WTI) Spot Price Index as an approximation of oil prices in the U.S. The oil prices growth factor (OG) is constructed as the realized monthly first differences in the logarithm of the WTI Spot Price Index using the Equation below:

$$
O G_{t}=\ln \left[\frac{O G_{t}}{O G_{t^{-1}}}\right]
$$

Where Oil $_{t,}$ Oil $l_{t-1}$ are oil prices at time $t$ and $t-1$ respectively. The U.S. producer price index/crude petroleum series was obtained from GFD for the period 1/1998 to 12/2017.

Market index. Market portfolio usually used by asset pricing models to measure risk and to capture all the information available to the market, not captured by economic factors. The return on the market portfolio is defined as the monthly first difference in the logarithm of the national equity market portfolio using the following equation;

$$
R m_{t}=\ln \left[\frac{R m_{t}}{R m_{t-1}}\right]
$$

$R m_{t}$, and $R m_{t-1}$ are the return values of the market at time $t$ and $t-1$, respectively, in local currency. The series for national stock market portfolio was obtained from GFD for the period 1/1998 to 12/2017.

The market return portfolios $\left(R m_{t}\right)$ are in excess of local short-term interest rates, the latter is used as proxy for risk free $\left(R f_{t}\right)$ to measure excess returns for market portfolio. The short-term interest rate refers to the three-month Treasury bill.

\section{Empirical Results}

This section of the paper presents the effects of innovations in local risk factors on local industry returns in the U.S. by estimating Equation 1 using OLS (Ordinary-Least Square).

After choosing the best ARIMA model for each local macroeconomic risk factor, we subtracted the fitted values from the actual values to form the unexpected components of the series. The new variables thus created are unexpected measures for industrial production, inflation, term structure, foreign exchange, and oil price changes in addition to local Market Index. After deriving innovations for the local macroeconomic risk factors, their influences on the stock price indices for all five local industries were estimated and tested. OLS was applied to estimate Equation (1) over the sample period. 
Table 2 presents descriptive statistics for the U.S. market index and macroeconomic risk factors for the period $1 / 1998$ to $12 / 2017$. The results show that the unexpected inflation carries the highest risk, while the unexpected industrial production carries the lowest level of risk as measured by the standard deviation.

Given that time series data were used, we also checked for stationarity of the series applying the ADF test. Results suggest that all the unexpected macroeconomic risk factors are stationary (I-0) at the $1 \%$ level of significance as shown in Table 3.

Table 2

Summary Statistics for Market Index and Macroeconomic Risk Factor (January 1998 to December 2017)

\begin{tabular}{lllllll}
\hline Statistics & UIP & UI & UTS & UFX & UOG & MKT \\
\hline Mean & $2.70 \mathrm{E}-06$ & $3.91 \mathrm{E}-05$ & $-5.22 \mathrm{E}-05$ & $2.37 \mathrm{E}-06$ & $-2.80 \mathrm{E}-07$ & -0.016969 \\
Median & -0.000240 & 0.004898 & -0.000261 & $5.49 \mathrm{E}-05$ & 0.003650 & -0.012483 \\
Maximum & 0.008219 & 1.133296 & 0.008925 & 0.029965 & 0.099247 & 0.044331 \\
Minimum & -0.017596 & -1.549675 & -0.007802 & -0.015416 & -0.116956 & -0.116139 \\
Std. dev. & 0.002576 & 0.344699 & 0.002839 & 0.005457 & 0.036492 & 0.027842 \\
Jarque-Bera & 869.6709 & 88.73163 & 12.44959 & 101.0430 & 3.831990 & 10.84024 \\
Probability & 0.000000 & 0.000000 & 0.001980 & 0.000000 & 0.147195 & 0.004427 \\
Observations & 240 & 240 & 240 & 240 & 240 & 240 \\
\hline
\end{tabular}

Table 3

Augmented Dickey-Fuller (ADF) Test on Macroeconomic Risk Factors (January 1998 to December 2017)

\begin{tabular}{|c|c|c|c|c|c|c|}
\hline Statistics & UIP & $\mathrm{UI}$ & UTS & UFX & UOG & MKT \\
\hline Level & $-15.13093^{* * *}$ & $-15.34196^{* * *}$ & $-15.38245^{* * *}$ & $-15.46417^{* * *}$ & $-15.40785^{* * * *}$ & $-9.46417^{* * *}$ \\
\hline
\end{tabular}

Note. The ADF Test is Augmented Dickey-Fuller Unit Root Test. The ADF test is a test of stationarity. The critical values for ADF test are $-2.5799,-2.8861$, and -3.4866 for significant levels of $10 \%, 5 \%$, and $1 \%$ respectively. ${ }^{*},{ }^{* *},{ }^{* * *}$ denote significance at $10 \%, 5 \%$, and $1 \%$ level, respectively.

Table 4 presents the correlation matrices for the U.S. monthly market index and unexpected macroeconomic risk factors which are very low 0.25 or under. The highest correlation, 0.253194 , found between unexpected term structure and the market index and it is not significant. Thus, Table 4 suggests absence of multi-collinearity.

Table 4

Correlation Matrix for Market Index and Macroeconomic Risk Factors (January 1998 to December 2017)

\begin{tabular}{lllllll}
\hline & UIP & UI & UTS & UFX & UOG & MKT \\
\hline UIP & 1.000000 & & & & & \\
UI & 0.021724 & 1.000000 & & & & \\
UTS & -0.080121 & 0.052795 & 1.000000 & & & \\
UFX & 0.041203 & -0.051245 & 0.051365 & 1.000000 & & \\
UOG & 0.015923 & 0.154047 & 0.067619 & -0.353126 & 1.000000 & 1.000000 \\
MKT & -0.027319 & 0.064446 & 0.253194 & -0.211015 & 0.049341 & \\
\hline
\end{tabular}

Note. Local macroeconomic risk factors are unexpected industrial production (UIP), unexpected Inflation (UI), the unexpected term structure (UTS), Unexpected Foreign exchange (UFX), unexpected oil price changes (UOG), and stock market index (MKT).

Table 5 reports industrial stock return reactions to several local macroeconomic risk factors in the U.S. for the sample period. The results show that the market index has significant and positive effect on each of the industries under study. However, the other variables show different relationships between macroeconomic risk 
factors and industry stock returns.

Unexpected term structure (UTS) affects both the banking industry and the chemicals industry positively and significantly at the $10 \%$ level of significance whereas it does not have effects on the other three industries. Unexpected Inflation (UI) found to have a negative and significant effect on the utility industry at the $10 \%$ level of significance but no effects on the other industries. Unexpected industrial production (UIP) also has a positive and significant effect on the U.S. chemicals industry at the $10 \%$ level of significance but no influence on the other industries was noticed. Both unexpected exchange rate (UFX) and unexpected oil prices (UOG) have no impact on any industry in the study.

The $R^{2}$ and $D W$ across the five estimated regressions in the U.S. point to high explanatory power of the models and absence of autocorrelations. It is quite interesting to see some similarities and differences among five industries. 
Table 5

Industrial Stock Returns Reactions to Local Macroeconomic Risk Factors for U.S. (January 1998 to December 2017)

\begin{tabular}{|c|c|c|c|c|c|c|c|c|c|c|c|}
\hline Indu-stry & Constant & UIP & $\mathrm{UI}$ & UTS & UFX & UOG & MKT & $N$ & $R^{2}$ adj & DW & $\mathrm{R}^{2} \mathrm{MKT}$ \\
\hline Banking & $\begin{array}{l}-0.0019 \\
(-1.0038)\end{array}$ & $\begin{array}{l}0.65748 \\
(1.0145)\end{array}$ & $\begin{array}{l}-0.0051 \\
(-1.0448)\end{array}$ & $\begin{array}{l}1.2318 \\
(2.5864)^{*}\end{array}$ & $\begin{array}{l}0.4668 \\
(1.3881)\end{array}$ & $\begin{array}{l}0.0408 \\
(0.0408)\end{array}$ & $\begin{array}{l}0.9640 \\
(15.170)^{* * *}\end{array}$ & 240 & 0.5297 & 2.0831 & 0.5222 \\
\hline Che-micals & $\begin{array}{l}-8.66 \mathrm{E}- \\
(-0.0686)\end{array}$ & $\begin{array}{l}0.8589 \\
(2.5722)^{*}\end{array}$ & $\begin{array}{l}-0.0022 \\
(-0.7169)\end{array}$ & $\begin{array}{l}0.9518 \\
(2.6238)^{*}\end{array}$ & $\begin{array}{l}-0.2512 \\
(-1.1679)\end{array}$ & $\begin{array}{l}-0.0235 \\
(-0.7431)\end{array}$ & $\begin{array}{l}0.9648 \\
(23.736)^{* * *}\end{array}$ & 240 & 0.74101 & 2.1614 & 0.7351 \\
\hline Insu-rance & $\begin{array}{l}-0.0011 \\
(-0.7137)\end{array}$ & $\begin{array}{l}0.5950 \\
(1.1229)\end{array}$ & $\begin{array}{l}-0.0059 \\
(-1.4969)\end{array}$ & $\begin{array}{l}-0.8043 \\
(-1.6022)\end{array}$ & $\begin{array}{l}-0.04900 \\
(-0.0490)\end{array}$ & $\begin{array}{l}0.03082 \\
(0.7622)\end{array}$ & $\begin{array}{l}0.9700 \\
(18.667)^{* * *}\end{array}$ & 240 & 0.6126 & 2.1962 & 0.6094 \\
\hline Tele-com & $\begin{array}{l}-0.0018 \\
(-1.2316)\end{array}$ & $\begin{array}{l}0.1469 \\
(0.2917)\end{array}$ & $\begin{array}{l}0.0047 \\
(1.2605)\end{array}$ & $\begin{array}{l}0.1095 \\
(0.2286)\end{array}$ & $\begin{array}{l}0.1167 \\
(0.4468)\end{array}$ & $\begin{array}{l}-0.0712 \\
(-1.8528)\end{array}$ & $\begin{array}{l}0.9301 \\
(18.797)^{* * *}\end{array}$ & 240 & 0.6266 & 2.0981 & 0.6252 \\
\hline Utility & $\begin{array}{l}0.0005 \\
(0.3471)\end{array}$ & $\begin{array}{l}0.6475 \\
(1.2828)\end{array}$ & $\begin{array}{l}-0.0099 \\
(-2.6161) *\end{array}$ & $\begin{array}{l}-0.5028 \\
(-1.0515)\end{array}$ & $\begin{array}{l}-0.4049 \\
(-1.5457)\end{array}$ & $\begin{array}{l}-0.0679 \\
(-1.7636)\end{array}$ & $\begin{array}{l}1.0895 \\
(22.010)^{* * *}\end{array}$ & 240 & 0.6969 & 2.0503 & 0.6831 \\
\hline
\end{tabular}

Note. Independent variables are unexpected industrial production (UIP), unexpected inflation rate (UI), unexpected term structure (UTS) unexpected foreign exchange rate (UFX), unexpected oil prices changes (UOG), and stock market index (MKT). T-Values (in parenthesis). $N$ is the number of observations for each local industry. DW is Durbin-Watson statistic. ${ }^{*}{ }^{*}{ }^{* *}$ Denote significance at the $10 \%, 5 \%, 1 \%$ level respectively. $R^{2}$ is the coefficient of determination adjusted for degrees of freedom. 


\section{Discussions and Conclusions}

Pricing of financial assets has intrigued researchers in the area of finance for a long time. Previous work in this area employed Capital Asset Pricing Model (CAPM) and Arbitrage Pricing Theory (APT), to assess assets' systematic risk. Further, most literature in this area investigated the effect of different sets of risk factors on the returns of individual or portfolios of stocks, regardless of industry type. Investigating the returns at the industry level is of interest in its own right. In this study, we employ a multifactor pricing model to investigate effects of several macroeconomic risk factors on industry returns in the U.S. Using monthly data from 1998:01 to 2017:12 and an ARIMA model, macroeconomic risk factors constructed from industrial production, inflation, term structure, foreign exchange rate, and oil prices were tested on the banking, chemicals, insurance, telecommunication, and utilities industries.

Results showed that the correlation between the market factors and macroeconomic risk factors was low. They also showed that the banking, chemical and telecommunication industries revealed more differences in their stock reactions to local macroeconomic risk factors. The insurance and telecommunication industries do not react significantly to risk factors. However, all the industries show strong reactions to local market portfolio. From policy perspectives, the significant relationships between the risk factors and industries' stock returns can serve as useful information to investors and practitioners in better understanding of how and to what extent risk factors affect returns by industries. Such information can help them make decision in allocation, timing, and diversification of investment portfolios.

\section{References}

Abugri, Benjamin A. (2008). Empirical relationship between macroeconomic volatility and stock returns: evidence from Latin American markets. International Review of Financial Analysis, Elsevier, 17(2), 396-410.

Black, F., Jensen, M. C., \& Scholes, M. (1972). The capital asset pricing models, empirical tests, in studies in the theory of capital markets. (M. C. Jensen, Ed.). New York: Praeger.

Chen, N. F., Roll, R., \& Ross, S. (1986). Economic forces and the stock market. Journal of Business, 59, 383-403.

Elhusseiny, M. F. (2009). The industry stock return reaction to risk factors: empirical evidence from Canadian stock market. International Journal of Business, Accounting, and Finance, 3(1), 48-59.

Fama, E. F., \& French, K. R. (1992). The cross-section of expected stock returns. Journal of Finance, 47(2), 427-466.

Fama, E. F., \& MacBeth, J. D. (1973). Risk, return and equilibrium: Empirical tests. Journal of Political Economy, 81, $607-636$.

Lintner, J. (1965). The valuation of risk assets and selection of risky investments in stock portfolios and capital budgets. Review of Economics and Statistics, 47, 13-37.

McSweeney, E. J., \& Worthington, A. C. (2008). A comperative analysis of oil as a risk factor in Australian industry stock returns, 1980-2006. Studies in Economics and Finance, 25(2), 131-145.

Mohantya, S. K., Nandhab, M., Turkistanic, A. Q., \& Alaitanic, M. Y. (2011). Oil price movements and stock market returns: Evidence from Gulf Cooperation Council (GCC) countries. Global Finance Journal, 22, 42-55.

Mutuku, C., \& Ng'eny, K. L. (2015). Macroeconomic variables and the Kenyan equity market: A time series analysis. Journal of Business and Economic Research, 5(1), 1-10.

Norbert Funke \& Akimi Matsuda (2006). Macroeconomic news and stock returns in the United States and Germany. German Economic Review, 7, 189-210.

Roll, R. (1977). A critique of the asset pricing theories' tests-Part 1: On past and potential testability of the theory. Journal of Financial Economics, 4, 129-176.

Roll, R., \& Ross, S. A. (1980). An empirical investigation of the arbitrage pricing theory. The Journal of Finance, 35(5), 1073-1103.

Sangmi, M., \& Hassan, M. M. (2013). Macroeconomic variables on stock market interactions: The Indian experience. Journal of Business and Management, 11(3), 15-28. 
Sharp, W. F. (1964). Capital assets prices: A theory of market equilibrium under conditions of risk. Journal of Finance, 19, 425-442.

Yu, H., \& Hsieh, W. J. (2012). Impacts of macroeconomic variables on the stock market index in Poland: New evidence. Journal of Business Economics and Management, 13(2), 334-343. 